Published in final edited form as:

Osteoporos Int. 2012 April ; 23(4): 1381-1390. doi:10.1007/s00198-011-1723-x.

\title{
Ethnic differences in composite indices of femoral neck strength
}

\author{
S. Ishii, \\ Geriatric Research, Education and Clinical Center (GRECC), VA Greater Los Angeles Healthcare \\ System, 11301 Wilshire Blvd, Building 220, Room 302, Los Angeles, CA 90073, USA
}

J. A. Cauley,

Department of Epidemiology, Graduate School of Public Health, University of Pittsburgh, 130

DeSoto Street, A524 Crabtree, Pittsburgh, PA 15260, USA

\section{G. A. Greendale,}

Department of Medicine/Division of Geriatrics, David Geffen School of Medicine at UCLA, 10933

Le Conte Ave, Los Angeles, CA 90095, USA

M. E. Danielson,

Department of Epidemiology, Graduate School of Public Health, University of Pittsburgh, 130

DeSoto Street, A524 Crabtree, Pittsburgh, PA 15260, USA

N. Safaei Nili, and

Department of Medicine/Division of Geriatrics, David Geffen School of Medicine at UCLA, 10933

Le Conte Ave, Los Angeles, CA 90095, USA

A. Karlamangla

Department of Medicine/Division of Geriatrics, David Geffen School of Medicine at UCLA, 10933

Le Conte Ave, Los Angeles, CA 90095, USA

S. Ishii: sishii@ucla.edu

\section{Abstract}

Summary-Bone mineral density does not explain race/ethnicity differences in hip fracture risk. In this study, we demonstrated that race/ethnicity differences in composite hip strength indices were consistent with documented race/ethnicity differences in hip fracture risk, suggesting that unlike bone density, the composite indices may represent ethnicity-independent measures of bone strength.

Introduction-African-American and Asian women have lower risks of hip fracture than Caucasian women, but such racial/ethnic variation in hip fracture risk cannot be explained by bone mineral density (BMD). The composite indices of femoral neck strength integrate femoral neck and body size with BMD and predict hip fracture risk in Caucasian women. We hypothesize that unlike race/ethnic differences in BMD, race/ethnic differences in the composite strength indices would be consistent with race/ethnic differences in hip fracture risk.

Methods-We studied a community-based sample of Caucasian ( $n=968)$, African-American $(n=512)$, Chinese $(n=221)$, and Japanese $(n=239)$ women, premenopausal or in early perimenopause, from the Study of Women's Health Across the Nation.

Results-Unadjusted indices were similar in Caucasian and African-American women but higher in Asian women. After adjusting for age, body mass index, and menopause status, all three

(C) International Osteoporosis Foundation and National Osteoporosis Foundation 2011

Correspondence to: S. Ishii, sishii@ucla. edu.

Conflicts of interest None. 
minority groups had higher composite strength indices than Caucasian women. Foreign-born Japanese women had higher unadjusted and adjusted composite strength indices than US-born Japanese women, but such differences by nativity were not observed in Chinese women.

Conclusion-We concluded that composite strength indices have the potential to explain racial/ ethnic differences in hip fracture risk, suggesting that composite strength indices may represent ethnicity-independent measures of bone strength. This contention needs to be verified by further research on the fracture predictive ability of composite strength indices in multi-ethnic longitudinal cohorts.

\section{Keywords}

Bone size; Composite strength indices; Ethnic difference; Femoral neck strength; Hip geometry; Nativity

\section{Introduction}

There is substantial variation in the incidence of hip fracture across race/ethnicity groups, both nationally and internationally. In the USA, hip fracture rates are considerably higher in Caucasian women than in Asian, African- American, and Hispanic women [1-7]. Low bone mineral density (BMD), as measured by dual energy X-ray absorptiometry (DXA)[8], is the most reliable and validated predictor of hip fracture risk $[9,10]$ within race/ethnicity groups (including white women [3, 4, 11-19], white men [15, 16], African-American women [3, 4, 11, 16], African- American men [16], Asian women [3, 11, 20], Asian men [20], and Hispanic women $[3,11])$. However, low BMD fails to account for inter-racial variation in hip fracture risk. For example, although Japanese women have lower BMD than white women [21-24], they have lower risk of hip fracture than white women [1, 2]. One largescale multi-ethnic longitudinal study demonstrated that African- American and Asian women had lower risks of fracture than white women, even after adjusting for weight, BMD, and other clinically important factors [11].

This inability to capture inter-racial variation in hip fracture risk with BMD alone or in combination with other measured variables has meant that clinicians have to include race/ ethnicity information to predict their patient's hip fracture risk, either in the form of ethnicity-specific T-scores and Z-scores [25] or nation- and ethnicity-specific web-based fracture risk calculators (http://www.shef.ac.uk/FRAX/index.htm).

Unfortunately, the use of race/ethnicity in predicting an individual's fracture risk is problematic for a variety of reasons. First, ethnicity is often poorly defined, and diverse ethnic subgroups are frequently categorized under a single label (e.g., Asian-American, which includes disparate ethnic groups from East, Southeast, South, and West Asia) [2628]. Second, ethnicity is often used as a proxy for unmeasured individual factors such as genetics, family history, and lifestyle, in order to capture inter-ethnicity differences in these factors [27]. Findings obtained with such usage of race/ethnicity variables may lack validity if the unobserved factors are not homogenous within an ethnic group. Third, our ability to gauge fracture risk is predicated on knowing the individual's race/ethnicity-a difficult proposition for those from mixed ethnic backgrounds—and on the availability of a BMD reference database for that race/ethnicity group. Therefore, the use of race/ethnicity, although useful in population-based studies, may not be appropriate for predicting individual patients' fracture risk.

Body size and femoral neck geometry predict fracture risk independent of BMD [29-31] and vary significantly by race/ethnicity. Composite indices of femoral neck strength [32] integrate body size and bone size with bone density (the latter two are obtained from hip 
DXA scans) to capture the major structural contributions to bone strength (from bone density and bone size) relative to loads applied to bone during falls (proportional to body weight and height). The composite indices are inversely associated with incident hip fracture in community-dwelling Caucasian women [32]. We hypothesize that race/ethnic differences in fracture risk are mostly due to differences in bone strength relative to load (and less due to race/ethnic differences in fall risk) and postulate that the composite indices of femoral neck strength will allow hip fracture risk stratification in an ethnicity-independent manner. Thus, we propose that composite indices of hip strength could allow hip fracture risk assessment in individuals of unclear/mixed ethnicity and in under-represented race/ethnic groups that do not have a BMD reference database. The ideal test of this thesis would be to evaluate whether composite hip strength indices predict fractures in a sample of persons from diverse ethic/racial backgrounds. However, as an interim step, construct validity of the idea would be supported if inter-ethnic differences in composite strength indices were consistent with known inter-ethnic differences in hip fracture risk. This study was designed to test this latter contention.

We used baseline data from the Study of Women's Health Across the Nation (SWAN) to examine differences in composite strength indices among women from four race/ethnicity groups (African-American, Caucasian, Chinese, and Japanese) enrolled in a longitudinal study of menopause and midlife. At SWAN baseline, women were aged 42-53 years and were either premenopausal or early perimenopausal. The associations between race/ethnicity and bone strength are minimally confounded by menopause status in SWAN, because menopause-transition-associated changes in BMD do not occur until late perimenopause and postmenopause [33]. We hypothesized that the composite strength indices would be higher in Japanese, Chinese, and African-American women compared with Caucasian women, consistent with known inter-ethnic differences in hip fracture risk.

\section{Methods}

SWAN is a multi-center, multi-ethnic longitudinal study designed to characterize the biological and psychosocial changes that occur during the menopausal transition. In brief, criteria for entry included: age 42-53 years, no surgical removal of the uterus and/or both ovaries, not currently using exogenous hormone preparations affecting ovarian function, at least one menstrual period in the 3 months before enrollment, self-identification as a member of one of five ethnic groups-Caucasian, African-American, Hispanic, Chinese, or Japanese [34]. Participants were enrolled in 1996/1997 at seven clinical sites. Five sites enrolled women into the SWAN bone study and obtained DXA scans of the spine and hip: Boston, Massachusetts; Detroit, Michigan; Los Angeles, California; Oakland, California; and Pittsburgh, Pennsylvania. All five SWAN bone study sites enrolled Caucasians, and each site also enrolled women belonging to one pre-specified minority ethnic groupAfrican-American in Boston, Detroit, and Pittsburgh and Japanese and Chinese in Los Angeles and Oakland, respectively. The five sites together enrolled 2,413 women from four ethnic groups into the bone study cohort, 46 of whom did not get hip BMD measurement because they weighed more than $136 \mathrm{~kg}$ (the maximum allowed on the DXA machines). Femoral neck size measurements on archived hip DXA scans were made, as part of the SWAN Hip Strength Sub-Study, on 1,940 women (968 Caucasian, 512 African-American, 239 Japanese, 221 Chinese) who had a baseline hip DXA scan and two or more follow-up hip DXA scans in longitudinal follow-up. The SWAN and sub-study protocols were approved by the Institutional Review Board at each site, and all participants gave written informed consent. 


\section{Measurements}

Demographic data, health behavior data (including information on physical activity and smoking), and medication use data were obtained with standardized interviews and selfreported questionnaires. Height and weight were measured using a fixed stadiometer and a digital scale with the participants wearing light clothing and no shoes. Body mass index (BMI) was calculated as weight (kilograms) divided by the square of height (meters).

DXA scans of the hip were acquired using standardized protocols and cross-calibrated Hologic QDR 4500 or Hologic QDR 2000 scanners (Hologic Inc., Waltham, MA, USA) and OsteoDyne's Hip Positioner System (Osteodyne, Inc.) The quality control program for DXA in SWAN has been previously described [33]. The projected (areal) BMD in the femoral neck was recorded. Femoral neck axis length (FNAL) is the distance along the femoral neck axis from the lateral margin of the base of the greater trochanter to the apex of the femoral head. Femoral neck width (FNW) is the smallest thickness of the femoral neck along any line perpendicular to the femoral neck axis (Fig. 1). Measurements of FNAL and FNW were performed using the region of interest (ROI) window, which was repositioned and resized by the DXA operator so that a side of the ROI window spanned the geometric measures of interest. Then, the pixel locations of relevant window corners were recorded and used to calculate the relevant distances in millimeters, using pixel dimensions provided by the manufacturer, Hologic, Inc. Composite indices of femoral neck strength are designed to capture bone strength, which is derived from bone size (FNAL and FNW) and bone density (BMD), relative to the size of load during a fall, which is assumed to be proportional to body size (weight and height), and calculated using the following formulas [32]:

$$
\begin{aligned}
& \text { Compression strength index }(\mathrm{CSI})=\frac{\mathrm{BMD} \times \mathrm{FNW}}{\text { weight }} \\
& \text { Bending strength index }(\mathrm{BSI})=\frac{\mathrm{BMD} \times \mathrm{FNW}^{2}}{\mathrm{FNAL} \times \text { weight }} \\
& \text { Impact strength index }(\text { ISI })=\frac{\mathrm{BMD} \times \mathrm{FNW} \times \mathrm{FNAL}}{\text { height } \times \text { weight }}
\end{aligned}
$$

CSI reflects the ability of the femoral neck to withstand an axial compressive load, BSI reflects its ability to withstand bending forces, and ISI reflects the ability of the femoral neck to absorb the energy of impact in a fall from standing height. To examine reproducibility, 20 women volunteers were scanned twice on the same day with repositioning, and femoral neck BMD, FNW, and FNAL were measured twice. Intraclass correlation coefficients for the three indices were all greater than 0.98 .

\section{Statistical analysis}

The distributions of the composite strength indices were examined and confirmed to be normal (skew 0.38 for CSI, 0.63 for BSI, 0.42 for ISI, kurtosis 0.32 for CSI, 1.0 for BSI, 0.31 for ISI). Means of the composite strength indices in each of the three non-Caucasian groups were compared to the means in Caucasian women, using unmatched $t$ tests. Multiple linear regression was used to adjust for potential confounders. Because our aim was to examine if race/ethnicity differences in the strength indices were consistent with known 
race/ethnicity differences in hip fracture risk, we first adjusted for factors that might confound the association between bone strength and hip fracture risk. Most hip fractures occur as a result of a fall [35]; thus fall risk and the amount of soft tissue padding over the hip (which absorbs some impact energy) are related to hip fracture risk [36]. Hence, we adjusted for age (continuous) - a risk factor for falls [37], and BMI—a surrogate for relative soft tissue mass (categorized as "low $(B M I<22)$," "normal $(22 \unlhd B M I<25)$," "overweight $(25 \leq \mathrm{BMI}<30)$," "obese (30 $\mathrm{BMI})$ "). In addition, because age at menopause can vary by race/ethnicity, we included adjustment for menopause status (pre vs. early peri). To control for measurement variability by study site and scanner type, we also adjusted for type of DXA scanner (Hologic 4500 vs. 2000) and study site. Because BMI was substantially different between race/ethnicity groups, we tested if race/ethnicity differences in strength indices varied by BMI, by including race/ethnicity $\times$ BMI interactions.

We next examined several factors as potential sources for the race/ethnicity differences in strength indices, by adding them to the models to test if and how much they explained the race/ethnicity differences in composite strength indices. In this step, we added smoking status (never, past, current), physical activity (a summary score of active living, home, and recreational physical activity was dichotomized at the median [38]), and medication use (none vs. any for oral steroids, supplementary vitamin D, and calcium) [39].

Previous studies have found that foreign-born Japanese and Chinese American women had lower areal BMD compared with US-born counterparts or white women [40-42]. Place of birth is a surrogate marker reflecting the environmental differences early in life before the peak bone mass is achieved [43]. To examine the effect of birthplace on the composite strength indices, we compared the mean values of the composite strength indices in US-born Japanese and Chinese participants with those of foreign-born Japanese and Chinese participants, using unmatched $t$ tests. Multiple linear regression analysis was employed to adjust for covariates.

\section{Results}

Distributions of characteristics across race/ethnicity are shown in Table 1. Japanese women were slightly older than African-American women but of similar age as Caucasian and Chinese women; Chinese and Japanese women were shorter and weighed less than Caucasians or African-American women. Compared with Caucasian women, AfricanAmerican women were of similar height, but had greater weight. Unadjusted femoral neck areal BMD was highest in African-American women, followed by Caucasians, and lowest in Chinese and Japanese women. FNAL was higher in Caucasians and African-American than in the Asian groups. FNW was lowest in Chinese women but similar among the remaining three groups.

In the complete sample, none of the composite strength indices were significantly correlated with femoral neck areal BMD; however, after stratification by race/ethnicity, in each race/ ethnicity group, each of the composite strength indices was positively and significantly correlated with BMD, with only two exceptions: BMD was not correlated with ISI in African-American and Chinese women.

\section{Between-ethnicity comparisons of composite strength indices}

Table 2 shows differences in unadjusted and adjusted means of composite strength indices between Caucasians and the other three race/ethnicity groups. Unadjusted means of all three composite indices were comparable between African-American and Caucasian women, but significantly higher in both Asian groups. The Chinese- Caucasian difference was 9\% (0.5 
standard deviation, SD) or more, and the Japanese-Caucasian difference was 16\% (1.0 SD) or more.

After adjusting for age, menopausal status, BMI, DXA scanner type (Hologic 4500 vs. 2000), and study site, all three minority groups had higher means of each of the three composite strength indices than Caucasian women (Table 2, model 2). Race/ethnicity $\times$ BMI interaction terms were not significant for all three indices. ( $p=0.76$ for CSI, 0.21 for BSI, 0.77 for ISI).

Differences in the composite strength indices between Caucasians and the other three groups did not diminish significantly after inclusion of smoking status, physical activity, and medication use in the model, suggesting that these factors did not explain the higher femoral neck strength in the three non Caucasian groups (Table 2, model 3).

\section{Within-ethnicity differences by place of birth}

US-born Chinese women were significantly higher, more physically active, and more likely to be either a current or past smoker than foreign-born Chinese women, but otherwise, there were no significant differences between these two groups. US-born and foreign-born Japanese women were of similar height, but US-born Japanese women weighed more and were more likely to be obese/ overweight than foreign-born Japanese (Table 3). There were no significant differences in femoral neck areal BMD, FNAL, or FNW by place of birth. Age at immigration was similar between Chinese and Japanese foreign-born women $(p=0.96)$.

Comparisons of composite strength indices by place of birth are shown in Table 4. Among Chinese women, there were no differences in hip strength indices by place of birth either before or after adjustment. Foreign-born Japanese women had significantly higher mean values of each of the three composite indices compared to US-born Japanese women; each of the indices was about $11 \%$ (or $0.8 \mathrm{SD}$ ) greater. This advantage for foreign-born Japanese women over their US-born counterparts persisted after adjusting for age, BMI categories, and menopause transition stage (Table 4, model 2). Further adjustment for smoking, physical activity, and medications did not diminish the difference in strength indices between US-born and foreign-born Japanese women (Table 3, model 3).

\section{Discussion}

In this cross-sectional study of 1,940 premenopausal/early-perimenopausal women from four ethnic groups, we examined inter-ethnic and within-ethnic differences by place of birth in femoral neck composite strength indices. These indices combine femoral neck BMD, body height and weight, and femoral neck size to quantify strength (resistance to fracture forces) relative to load (forces placed on the hip during a fall). We found that, consistent with known inter-ethnic differences in hip fracture risk, African-American, Chinese, and Japanese women have higher values on all three composite strength indices than Caucasian women. These differences were seen despite the lower BMD in both Japanese and Chinese women, compared to Caucasians, and the higher load (body weight) in African-American women compared to Caucasians.

The ethnic/racial differences in hip strength indices seen in this study were large: strength indices were at least 0.5 SD greater in Chinese than in Caucasian women and at least 1.0 SD higher in Japanese versus Caucasian women. In one study of Caucasian women, a $60 \%$ relative reduction in hip fracture risk was associated with each SD increment in composite strength indices [32]. If the composite indices confer similar protection in the ethnic groups studied here, the observed differences would translate to hip fracture relative risk reduction 
of $35 \%$ in Chinese compared to Caucasian women and $60 \%$ in Japanese compared to Caucasian women. These differences are consistent with reported differences in risks of fracture in these ethnic groups [11] and parallel US Medicare data showing that Chinese and Japanese women in the USA have fewer hip fracture hospitalizations than Caucasians [2].

We also found that foreign-born Japanese women had higher values of the three composite indices compared to US-born Japanese women. It is likely that US-born Japanese women and foreign-born Japanese women are similar in terms of genetic stock because Japan has been relatively isolated from the rest of the world for most of its history, and its genetic pool is relatively homogenous [44]. Therefore, the differences in values of femoral neck composite strength indices between US-born and foreign-born Japanese women may be attributable to environmental differences before they achieved the peak bone mass, since Japanese first-generation emigrants tend to have lifestyles and health behaviors more similar to those in Japan than subsequent-generation immigrants who are more westernized [1].

In contrast to the finding in Japanese women, birthplace did not make a significant difference in femoral neck strength indices for Chinese women. We explored possible explanations for the differential impact of birthplace in Japanese and Chinese women. Age at immigration was similar in Chinese and Japanese foreign-born women. Differences in health behaviors were observed between US-born women and foreign-born women, but adjusting for these factors did not account for femoral neck strength index differences between US-born and foreign-born Japanese women. Other potential reasons for the differential impact of birthplace in Japanese and Chinese women are differences in extent of acculturation and number of generations since immigration in the US-born women and the greater genetic heterogeneity in Chinese compared to Japanese [45].

However, the observed differences in the composite strength indices between US-born and foreign-born Japanese were not consistent with the previous study which showed comparable hip fracture rates between Japanese living in Okinawa, Japan, and Japanese living in Oahu, Hawaii [1]. However, the study was conducted in the 1980s and needs to be repeated since cohort differences may be more obvious today.

Our study has limitations that need to be acknowledged. First, the composite indices of hip strength employed in this study are structural measures based on macroscopic measurements from DXA scans and ignore microscopic features such as differences in the quality of cancellous mineralization and micro-architecture, both of which are important determinants of bone strength [46, 47]. In addition, the hip strength indices were derived using simplifying assumption that the femoral neck is a simple cylinder and do not take into account other aspects of shape such as femoral neck-shaft angle, which may be associated with hip fracture risks $[30,48]$. We also had to make simplifying approximations in the estimation of the load during a fall, ignoring the direction of fall and the role of protective reflexes. Second, this is an observational study, and although we adjusted for major factors known to influence fracture risk and bone strength, we cannot rule out the possibility that our results are confounded by unrecognized risk factors that vary between race/ethnicity groups. Third, this cohort is limited to women, and studies have shown that there are race/ ethnicity differences in bone strength in men also [24, 49]. Fourth, the DXA scanner used varied by study site: Hologic QDR 2000 versus QDR 4500. We adjusted for type of scanner to correct for measurement differences between scanners, but we could not determine in this study if there are systematic differences in measurements from the two scanners because of confounding by differences between participants from different sites. Further research into measurement differences between scanners is warranted. 
Despite these limitations, this study is, to our knowledge, the first study to demonstrate that African- American, Chinese, and Japanese women have higher values of hip strength, quantified using composite indices that assess bone strength relative to the load the hip is asked to bear. These differences are consistent with known inter-ethnicity differences in hip fracture risk, differences which cannot be explained by femoral neck areal BMD alone.

Inter-ethnic differences in a candidate ethnicity-independent fracture prediction index should be consistent with inter-ethnic differences in hip fracture risk (though it is just a necessary condition). To be sufficient, the predictive ability of such an index should be proved in longitudinal studies. What we demonstrated in this study was inter-ethnic differences in the composite strength indices are consistent with inter-ethnic differences in hip fracture risk, and therefore, the indices may potentially be candidates for race/ethnicity-independent fracture prediction. This is especially important in individuals of unknown or mixed ethnicity and in race/ ethnicity groups for which a BMD reference database is not yet available.

\section{Acknowledgments}

The Study of Women's Health Across the Nation (SWAN) has grant support from the National Institutes of Health (NIH), DHHS, through the National Institute on Aging (NIA), the National Institute of Nursing Research (NINR), and the NIH Office of Research on Women's Health (ORWH) (grants NR004061; AG012505, AG012535, AG012531, AG012539, AG012546, AG012553, AG012554, AG012495). Dr. Ishii was supported by VA Greater Los Angeles Healthcare System Geriatric Research, Education and Clinical Center; and VA Advanced Geriatrics Fellowship. The Hip Strength Through the Menopausal Transition has grant support from the NIA (AG026463). The SWAN Hip Strength Sub-Study has grant support from the NIA (AG028748). The content of this article is solely the responsibility of the authors and does not necessarily represent the official views of the NIA, NINR, ORWH, VA or the NIH. We thank the study staff at each of the following sites and all the women who participated in SWAN: Clinical centers: University of Michigan, Ann Arbor-MaryFran Sowers, PI; Massachusetts General Hospital, Boston, MA—Joel Finkelstein, PI 1999-present; Robert Neer, PI 1994-1999; Rush University, Rush University Medical Center, Chicago, IL-Howard Kravitz, PI 2009-present; Lynda Powell, PI 1994-2009; University of California, Davis/Kaiser-Ellen Gold, PI; University of California, Los Angeles—Gail Greendale, PI; Albert Einstein College of Medicine, Bronx, NY—Rachel Wildman, PI 2010; Nanette Santoro, PI 2004-2010; University of Medicine and Dentistry-New Jersey Medical School, Newark-Gerson Weiss, PI 1994-2004; and the University of Pittsburgh, Pittsburgh, PA—Karen Matthews, PI. NIH program office: National Institute on Aging, Bethesda, MD—Sherry Sherman 1994-present, Marcia Ory 1994- 2001; National Institute of Nursing Research, Bethesda, MD-Program Officers. Central laboratory: University of Michigan, Ann Arbor-Daniel McConnell (Central Ligand Assay Satellite Services). Coordinating center: University of Pittsburgh, Pittsburgh, PA -Kim Sutton-Tyrrell, PI 2001-present; New England Research Institutes, Watertown, MA—Sonja McKinlay, PI 1995-2001. Steering committee: Susan Johnson, Current Chair; Chris Gallagher, Former Chair.

\section{References}

1. Ross PD, Norimatsu H, Davis JW, Yano K, Wasnich RD, Fujiwara S, Hosoda Y, Melton LJ 3rd. A comparison of hip fracture incidence among native Japanese, Japanese Americans, and American Caucasians. Am J Epidemiol. 1991; 133(8):801-809. [PubMed: 2021147]

2. Lauderdale DS, Jacobsen SJ, Furner SE, Levy PS, Brody JA, Goldberg J. Hip fracture incidence among elderly Asian-American populations. Am J Epidemiol. 1997; 146(6):502-509. [PubMed: 9290511]

3. Siris ES, Miller PD, Barrett-Connor E, Faulkner KG, Wehren LE, Abbott TA, Berger ML, Santora AC, Sherwood LM. Identification and fracture outcomes of undiagnosed low bone mineral density in postmenopausal women: results from the National Osteoporosis Risk Assessment. Jama. 2001; 286(22):2815-2822. [PubMed: 11735756]

4. Cauley JA, Lui LY, Ensrud KE, Zmuda JM, Stone KL, Hochberg MC, Cummings SR. Bone mineral density and the risk of incident nonspinal fractures in black and white women. Jama. 2005; 293(17): 2102-2108. [PubMed: 15870413]

5. Robbins J, Aragaki AK, Kooperberg C, Watts N, Wactawski-Wende J, Jackson RD, LeBoff MS, Lewis CE, Chen Z, Stefanick ML, Cauley J. Factors associated with 5-year risk of hip fracture in postmenopausal women. Jama. 2007; 298(20):2389-2398. [PubMed: 18042916] 
6. Cauley JA, Wu L, Wampler NS, Barnhart JM, Allison M, Chen Z, Jackson R, Robbins J. Clinical risk factors for fractures in multi-ethnic women: the Women's Health Initiative. J Bone Miner Res. 2007; 22(11):1816-1826. [PubMed: 17638574]

7. Barrett JA, Baron JA, Karagas MR, Beach ML. Fracture risk in the U.S. Medicare population. J Clin Epidemiol. 1999; 52(3):243-249. [PubMed: 10210242]

8. Bouxsein ML, Seeman E. Quantifying the material and structural determinants of bone strength. Best Pract Res Clin Rheumatol. 2009; 23(6):741-753. [PubMed: 19945686]

9. Johnell O, Kanis JA, Oden A, Johansson H, De Laet C, Delmas P, Eisman JA, Fujiwara S, Kroger H, Mellstrom D, Meunier PJ, Melton LJ 3rd, O'Neill T, Pols H, Reeve J, Silman A, Tenenhouse A. Predictive value of BMD for hip and other fractures. J Bone Miner Res. 2005; 20(7):1185-1194. [PubMed: 15940371]

10. Kanis JA, Oden A, Johnell O, Johansson H, De Laet C, Brown J, Burckhardt P, Cooper C, Christiansen C, Cummings S, Eisman JA, Fujiwara S, Gluer C, Goltzman D, Hans D, Krieg MA, La Croix A, McCloskey E, Mellstrom D, Melton LJ 3rd, Pols H, Reeve J, Sanders K, Schott AM, Silman A, Torgerson D, van Staa T, Watts NB, Yoshimura N. The use of clinical risk factors enhances the performance of BMD in the prediction of hip and osteoporotic fractures in men and women. Osteoporos Int. 2007; 18(8):1033-1046. [PubMed: 17323110]

11. Barrett-Connor E, Siris ES, Wehren LE, Miller PD, Abbott TA, Berger ML, Santora AC, Sherwood LM. Osteoporosis and fracture risk in women of different ethnic groups. J Bone Miner Res. 2005; 20(2):185-194. [PubMed: 15647811]

12. Cummings SR, Black DM, Nevitt MC, Browner W, Cauley J, Ensrud K, Genant HK, Palermo L, Scott J, Vogt TM. Bone density at various sites for prediction of hip fractures. The Study of Osteoporotic Fractures Research Group. Lancet. 1993; 341(8837):72-75. [PubMed: 8093403]

13. Nevitt MC, Johnell O, Black DM, Ensrud K, Genant HK, Cummings SR. Bone mineral density predicts non-spine fractures in very elderly women. Study of Osteoporotic Fractures Research Group. Osteoporos Int. 1994; 4(6):325-331. [PubMed: 7696827]

14. Black DM, Cummings SR, Genant HK, Nevitt MC, Palermo L, Browner W. Axial and appendicular bone density predict fractures in older women. J Bone Miner Res. 1992; 7(6):633638. [PubMed: 1414481]

15. De Laet CE, Van Hout BA, Burger H, Weel AE, Hofman A, Pols HA. Hip fracture prediction in elderly men and women: validation in the Rotterdam study. J Bone Miner Res. 1998; 13(10): 1587-1593. [PubMed: 9783547]

16. Mackey DC, Eby JG, Harris F, Taaffe DR, Cauley JA, Tylavsky FA, Harris TB, Lang TF, Cummings SR. Prediction of clinical non-spine fractures in older black and white men and women with volumetric BMD of the spine and areal BMD of the hip: the Health, Aging, and Body Composition Study*. J Bone Miner Res. 2007; 22(12):1862-1868. [PubMed: 17708713]

17. Schott AM, Cormier C, Hans D, Favier F, Hausherr E, Dargent-Molina P, Delmas PD, Ribot C, Sebert JL, Breart G, Meunier PJ. How hip and whole-body bone mineral density predict hip fracture in elderly women: the EPIDOS Prospective Study. Osteoporos Int. 1998; 8(3):247-254. [PubMed: 9797909]

18. Stone KL, Seeley DG, Lui LY, Cauley JA, Ensrud K, Browner WS, Nevitt MC, Cummings SR. $\mathrm{BMD}$ at multiple sites and risk of fracture of multiple types: long-term results from the Study of Osteoporotic Fractures. J Bone Miner Res. 2003; 18(11):1947-1954. [PubMed: 14606506]

19. Taylor BC, Schreiner PJ, Stone KL, Fink HA, Cummings SR, Nevitt MC, Bowman PJ, Ensrud KE. Long-term prediction of incident hip fracture risk in elderly white women: study of osteoporotic fractures. J Am Geriatr Soc. 2004; 52(9):1479-1486. [PubMed: 15341549]

20. Fujiwara S, Kasagi F, Masunari N, Naito K, Suzuki G, Fukunaga M. Fracture prediction from bone mineral density in Japanese men and women. J Bone Miner Res. 2003; 18(8):1547-1553. [PubMed: 12929946]

21. Yano K, Wasnich RD, Vogel JM, Heilbrun LK. Bone mineral measurements among middle-aged and elderly Japanese residents in Hawaii. Am J Epidemiol. 1984; 119(5):751-764. [PubMed: 6609636] 
22. Norimatsu H, Mori S, Uesato T, Yoshikawa T, Katsuyama N. Bone mineral density of the spine and proximal femur in normal and osteoporotic subjects in Japan. Bone Miner. 1989; 5(2):213222. [PubMed: 2920241]

23. Nakamura T, Turner CH, Yoshikawa T, Slemenda CW, Peacock M, Burr DB, Mizuno Y, Orimo $\mathrm{H}$, Ouchi Y, Johnston CC Jr. Do variations in hip geometry explain differences in hip fracture risk between Japanese and white Americans? J Bone Miner Res. 1994; 9(7):1071-1076. [PubMed: 7942154]

24. Dennison E, Yoshimura N, Hashimoto T, Cooper C. Bone loss in Great Britain and Japan: a comparative longitudinal study. Bone. 1998; 23(4):379-382. [PubMed: 9763151]

25. Unnanuntana A, Gladnick BP, Donnelly E, Lane JM. The assessment of fracture risk. J Bone Joint Surg Am. 2010; 92(3):743-753. [PubMed: 20194335]

26. Hunt LM, Megyesi MS. Genes, race and research ethics: who's minding the store? J Med Ethics. 2008; 34(6):495-500. [PubMed: 18511627]

27. Winker MA. Race and ethnicity in medical research: requirements meet reality. J Law Med Ethics. 2006; 34(3):520-525. 480. [PubMed: 17144175]

28. O'Loughlin J. Understanding the role of ethnicity in chronic disease: a challenge for the new millennium. Cmaj. 1999; 161(2):152-153. [PubMed: 10439824]

29. Allolio B. Risk factors for hip fracture not related to bone mass and their therapeutic implications. Osteoporos Int. 1999; 9(Suppl 2):S9-S16. [PubMed: 10525720]

30. Calis HT, Eryavuz M, Calis M. Comparison of femoral geometry among cases with and without hip fractures. Yonsei Med J. 2004; 45(5):901-907. [PubMed: 15515202]

31. Karlsson KM, Sernbo I, Obrant KJ, Redlund-Johnell I, Johnell O. Femoral neck geometry and radiographic signs of osteoporosis as predictors of hip fracture. Bone. 1996; 18(4):327-330. [PubMed: 8726389]

32. Karlamangla AS, Barrett-Connor E, Young J, Greendale GA. Hip fracture risk assessment using composite indices of femoral neck strength: the Rancho Bernardo study. Osteoporos Int. 2004; 15(1):62-70. [PubMed: 14605798]

33. Finkelstein JS, Brockwell SE, Mehta V, Greendale GA, Sowers MR, Ettinger B, Lo JC, Johnston JM, Cauley JA, Danielson ME, Neer RM. Bone mineral density changes during the menopause transition in a multiethnic cohort of women. J Clin Endocrinol Metab. 2008; 93(3):861-868. [PubMed: 18160467]

34. Sowers, M.; Crawford, S.; Sternfeld, B.; Morganstein, D.; Gold, E.; Greendale, G.; Evans, D.; Neer, R.; Matthews, K.; Sherman, S.; Lo, A.; Weiss, G.; Kelsey, J. Menopause: biology and pathobiology. Academic; San Diego: 2000. Design, survey, sampling and recruitment methods of SWAN: a multi-center, multi-ethnic, community based cohort study of women and the menopausal transition.

35. Lauritzen JB. Hip fractures. Epidemiology, risk factors, falls, energy absorption, hip protectors, and prevention. Dan Med Bull. 1997; 44(2):155-168. [PubMed: 9151010]

36. Bouxsein ML, Szulc P, Munoz F, Thrall E, Sornay-Rendu E, Delmas PD. Contribution of trochanteric soft tissues to fall force estimates, the factor of risk, and prediction of hip fracture risk. J Bone Miner Res. 2007; 22(6):825-831. [PubMed: 17352651]

37. Thurman DJ, Stevens JA, Rao JK. Practice parameter: assessing patients in a neurology practice for risk of falls (an evidence-based review): report of the Quality Standards Subcommittee of the American Academy of Neurology. Neurology. 2008; 70(6):473-479. [PubMed: 18250292]

38. Baecke JA, Burema J, Frijters JE. A short questionnaire for the measurement of habitual physical activity in epidemiological studies. Am J Clin Nutr. 1982; 36(5):936-942. [PubMed: 7137077]

39. Waugh EJ, Lam MA, Hawker GA, McGowan J, Papaioannou A, Cheung AM, Hodsman AB, Leslie WD, Siminoski K, Jamal SA. Risk factors for low bone mass in healthy 40-60 year old women: a systematic review of the literature. Osteoporos Int. 2009; 20(1):1-21. [PubMed: 18523710]

40. Nomura A, Wasnich RD, Heilbrun LK, Ross PD, Davis JW. Comparison of bone mineral content between Japan-born and US-born Japanese subjects in Hawaii. Bone Miner. 1989; 6(2):213-223. [PubMed: 2765709] 
41. Lauderdale DS, Kuohung V, Chang SL, Chin MH. Identifying older Chinese immigrants at high risk for osteoporosis. J Gen Intern Med. 2003; 18(7):508-515. [PubMed: 12848833]

42. Babbar RK, Handa AB, Lo CM, Guttmacher SJ, Shindledecker R, Chung W, Fong C, Ho-Asjoe H, Chan-Ting R, Dixon LB. Bone health of immigrant Chinese women living in New York City. J Community Health. 2006; 31(1):7-23. [PubMed: 16482763]

43. Cooper C, Westlake S, Harvey N, Javaid K, Dennison E, Hanson M. Review: developmental origins of osteoporotic fracture. Osteoporos Int. 2006; 17(3):337-347. [PubMed: 16331359]

44. Takahashi K, Juji T, Miyazaki H. Determination of an appropriate size of unrelated donor pool to be registered for HLA-matched bone marrow transplantation. Transfusion. 1989; 29(4):311-316. [PubMed: 2655205]

45. Chen J, Zheng H, Bei JX, Sun L, Jia WH, Li T, Zhang F, Seielstad M, Zeng YX, Zhang X, Liu J. Genetic structure of the Han Chinese population revealed by genome-wide SNP variation. Am J Hum Genet. 2009; 85(6):775-785. [PubMed: 19944401]

46. Follet H, Boivin G, Rumelhart C, Meunier PJ. The degree of mineralization is a determinant of bone strength: a study on human calcanei. Bone. 2004; 34(5):783-789. [PubMed: 15121009]

47. Cauley JA, Danielson ME, Gregg EW, Vogt MT, Zmuda J, Bauer DC. Calcaneal ultrasound attenuation in older African-American and Caucasian-American women. Osteoporos Int. 1997; 7(2):100-104. [PubMed: 9166388]

48. Gnudi S, Ripamonti C, Gualtieri G, Malavolta N. Geometry of proximal femur in the prediction of hip fracture in osteoporotic women. Br J Radiol. 1999; 72(860):729-733. [PubMed: 10624337]

49. Tsai KS, Cheng WC, Sanchez TV, Chen CK, Chieng PU, Yang RS. Bone densitometry of proximal femur in Chinese subjects: gender differences in bone mass and bone areas. Bone. 1997; 20(4):365-369. [PubMed: 9108357] 


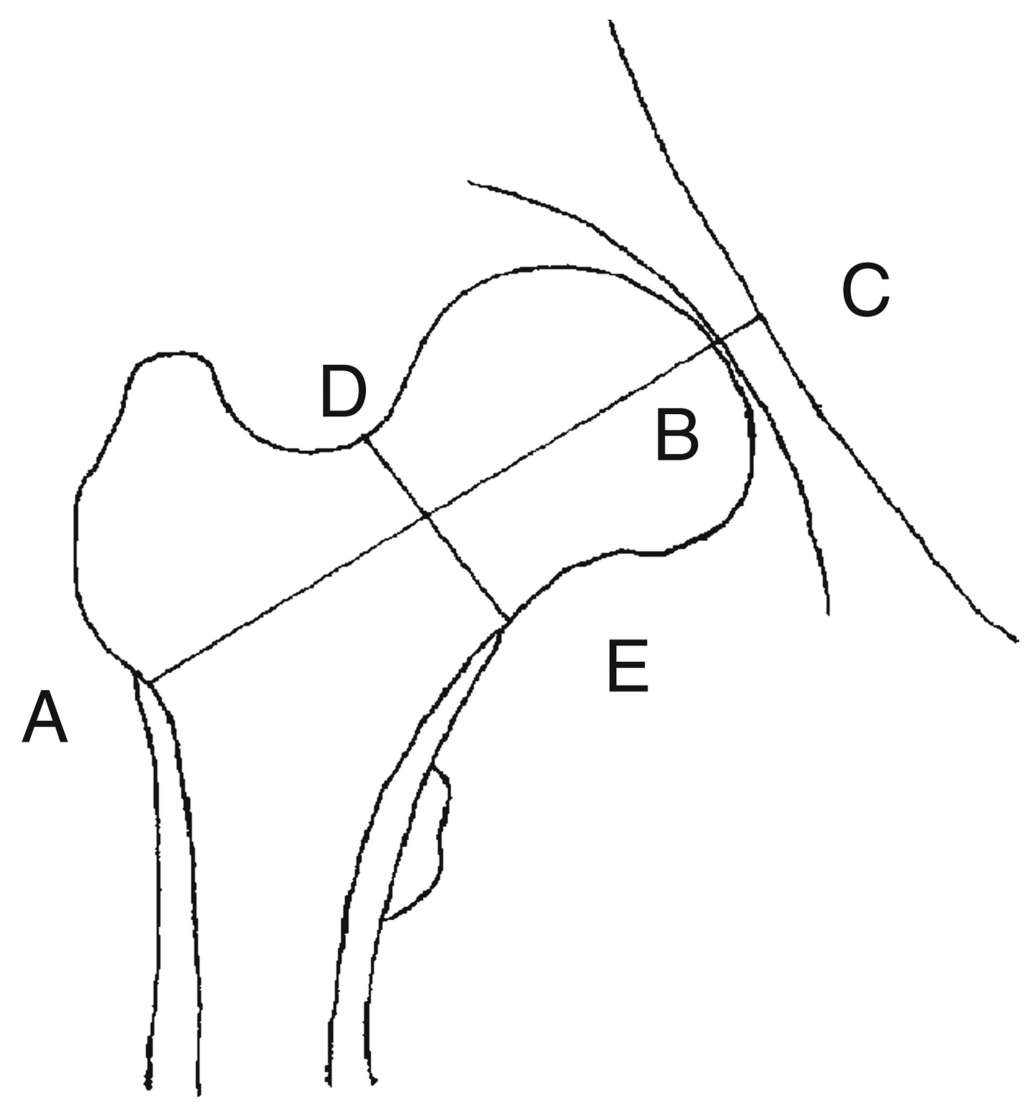

Fig. 1. Femoral neck size measurements. $A B$ is the femoral neck axis length (FNAL), and $D E$ is the femoral neck width (FNW) 


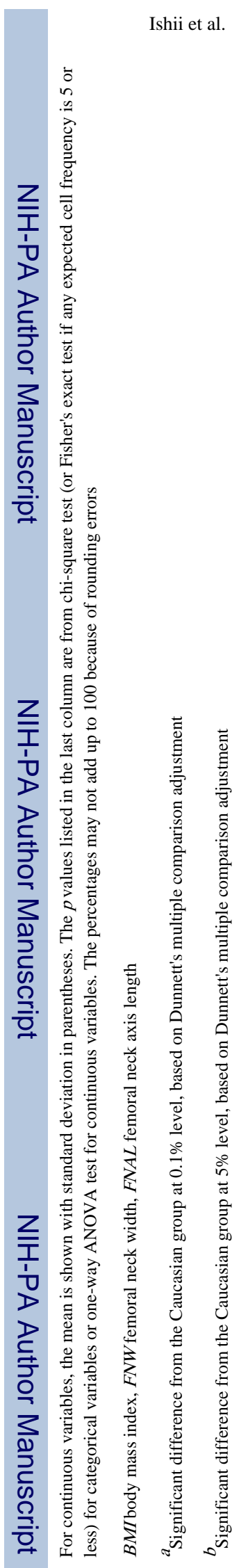

Osteoporos Int. Author manuscript; available in PMC 2013 April 01. 
Table 2

Differences in unadjusted and multiply-adjusted mean of hip strength indices in each ethnic/racial group

\begin{tabular}{lllll}
\hline & Caucasian (reference) & African-American & Chinese & Japanese \\
\hline CSI (g/kg-m) & & & & \\
Model 1 & 3.2 & $+0.01(-0.05,0.08)$ & $+0.35(0.25,0.43)^{a}$ & $+0.62(0.54,0.71)^{a}$ \\
Model 2 & 3.2 & $+0.19(0.14,0.24)^{a}$ & $+0.10(0.02,0.17)^{b}$ & $+0.23(0.16,0.30)^{a}$ \\
Model 3 & 3.3 & $+0.20(0.14,0.25)^{a}$ & $+0.14(0.06,0.22)^{a}$ & $+0.24(0.17,0.31)^{a}$ \\
BSI (g/kg-m) & & & & \\
Model 1 & 0.49 & $-0.000(-0.011,0.010)$ & $+0.046(0.032,0.060)^{a}$ & $+0.123(0.107,0.139)^{a}$ \\
Model 2 & 0.49 & $+0.021(0.011,0.030)^{a}$ & $+0.022(0.008,0.037)^{b}$ & $+0.062(0.049,0.075)^{a}$ \\
Model 3 & 0.49 & $+0.023(0.013,0.033)^{a}$ & $+0.029(0.014,0.044)^{a}$ & $+0.065(0.051,0.078)^{a}$ \\
ISI (g/kg-m) & & & & \\
Model 1 & 0.35 & $+0.001(-0.007,0.008)$ & $+0.037(0.028,0.047)^{a}$ & $+0.070(0.060,0.080)^{a}$ \\
Model 2 & 0.36 & $+0.022(0.016,0.028)^{a}$ & $+0.009(0.0001,0.018)^{c}$ & $+0.023(0.015,0.032)^{a}$ \\
Model 3 & 0.36 & $+0.022(0.016,0.028)^{a}$ & $+0.015(0.005,0.023)^{b}$ & $+0.025(0.017,0.034)^{a}$ \\
\hline
\end{tabular}

Model 1, unadjusted; model 2, adjusted for menopause status, BMI categories, age, DXA scanner type, and study site; mo del 3, adjusted for menopause status, BMI categories, age, smoking status, physical activity, medication use (oral steroid, supplementary vit D, and calcium), DXA scanner type, and study site

$B M I$ body mass index, $C S I$ compression strength index, BSI bending strength index, ISI impact strength index

${ }^{a}$ Significant difference at $0.1 \%$ level

$b_{\text {Significant difference at } 1 \% \text { level }}$

$c_{\text {Significant difference at } 5 \% \text { level }}$ 


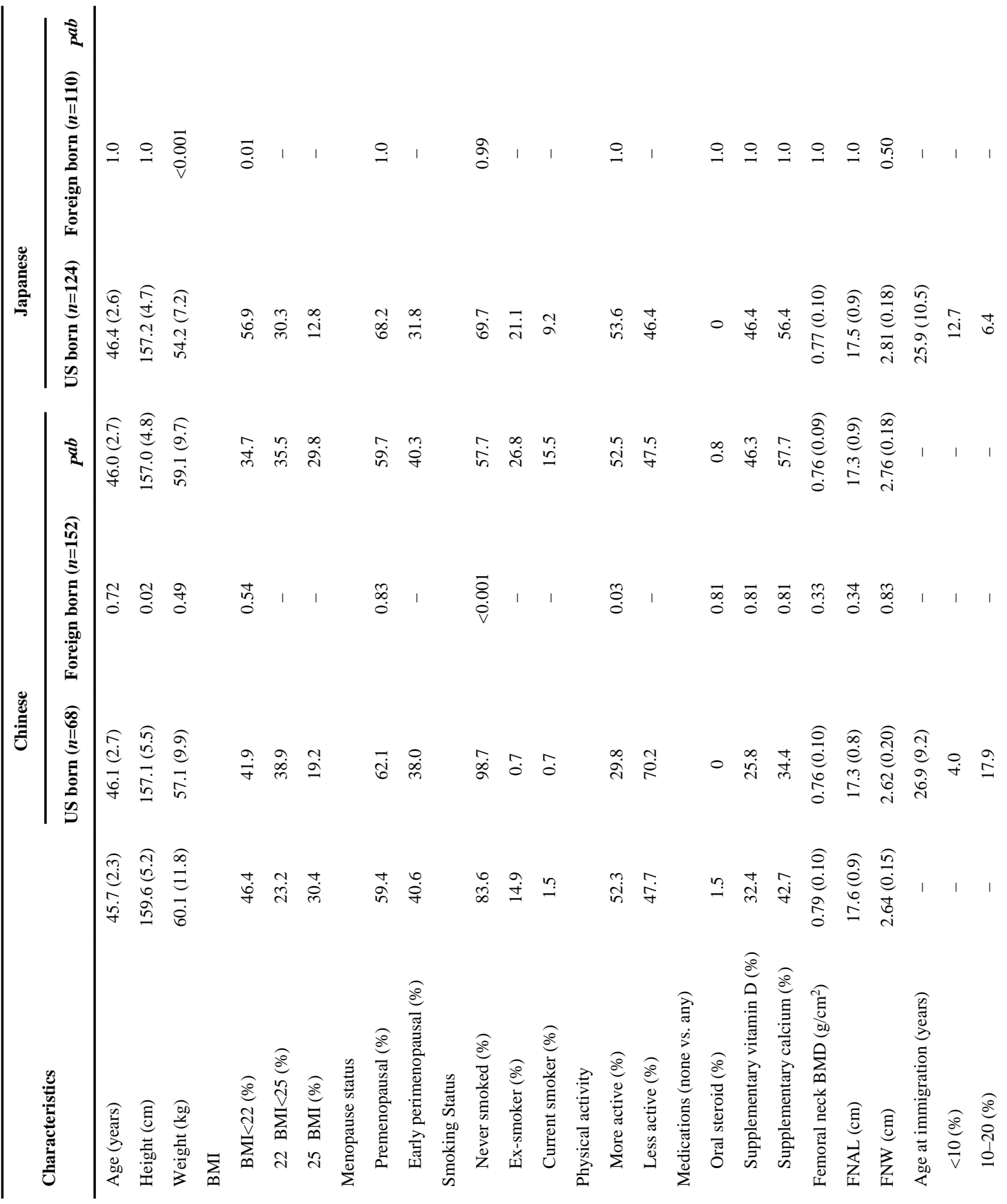




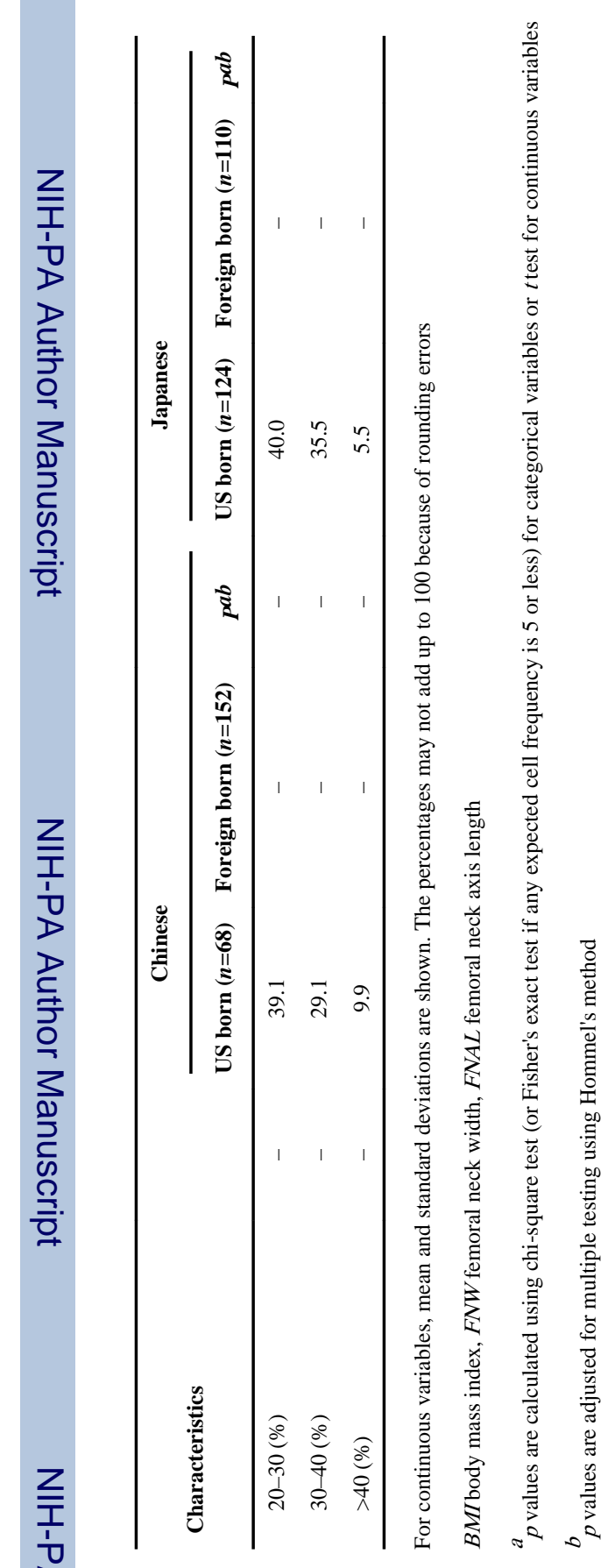

롤

Osteoporos Int. Author manuscript; available in PMC 2013 April 01. 


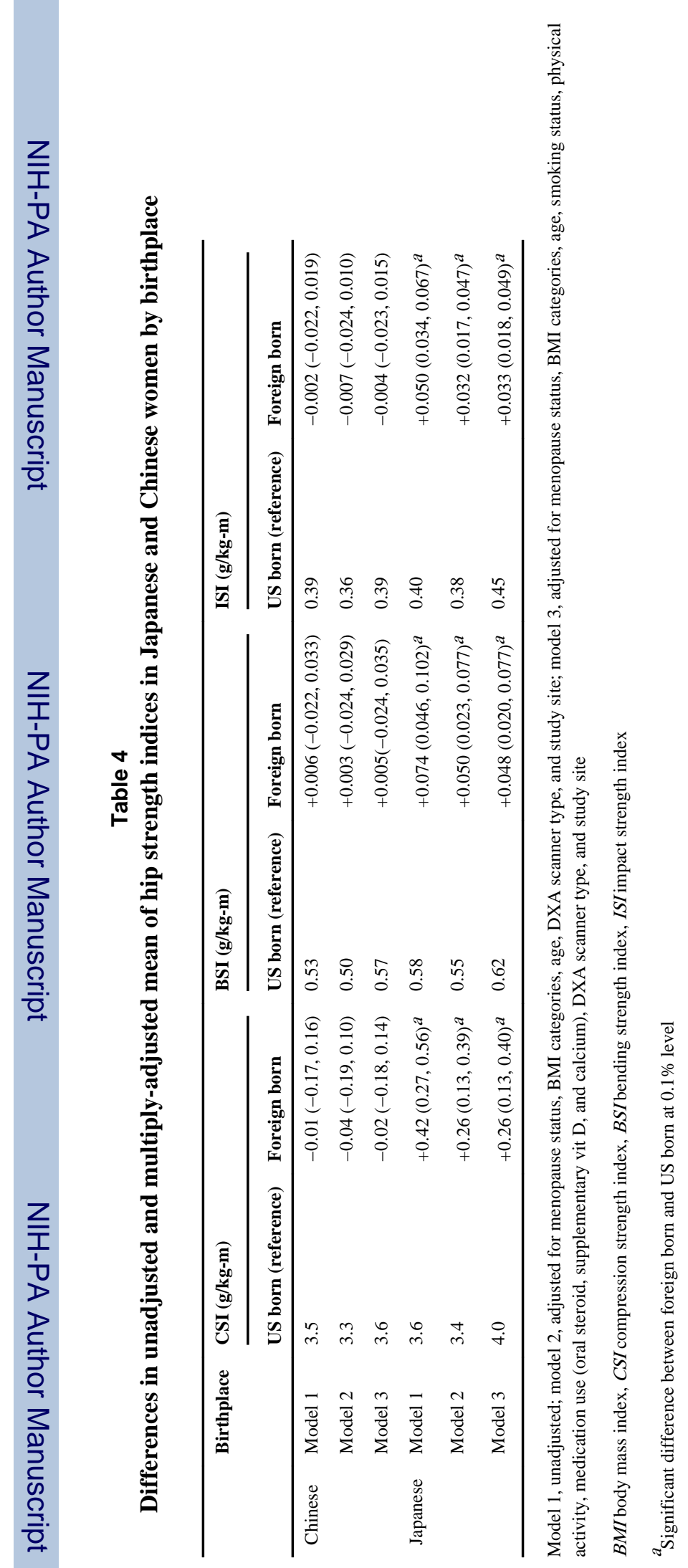

Osteoporos Int. Author manuscript; available in PMC 2013 April 01. 